\section{Brustkrebs: mehr Entscheidungssicherheit?}

Der Oncotype DX-Text wird weltweit bereits eingesetzt, obgleich randomisiert-kontrolliert gewonnene Studienergebnisse zur Risikoprädiktion beim Mammakarzinom noch fehlen. Jetzt belegen Daten aus Kanada, dass der Gentest die Therapieentscheidung deutlich verändern kann.

$\mathrm{n}$ einer kanadischen Feldstudie wurde der Test zur Bestimmung des 21-GenRecurrence-Scores (RS) bei Frauen mit Östrogenrezeptor-positivem, HER2negativem Brustkrebs mit höchstens Mikrometastasen der Lymphknoten durchgeführt, bei denen eine Entscheidung über eine adjuvante Chemotherapie anstand. Die Onkologen empfahlen auf Basis des Risikoabschätzungs-Systems Adjuvant! Online (AOL) eine endokrine Therapie mit oder ohne Chemotherapie, nach Vorliegen des RS erfolgte die endgültige Entscheidung.

Von 979 Patientinnen hatten laut RS $58 \%$ ein niedriges (RS 0-18), $33 \%$ ein intermediäres (RS 19-30) und 9\% ein hohes Risiko ( $R S \geq 31$ ). Die Therapieempfehlung der Onkologen blieb in $48 \%$ der Fälle gleich, in $38 \%$ führte der Test zum Verzicht auf eine unsichere oder klare Chemotherapieempfehlung, bei $15 \%$ von einer unsicheren oder keiner zu einer klaren Chemotherapieempfehlung. Insge- samt empfahlen die Onkologen nach dem Test für 238 Patientinnen eine Chemotherapie. Von den 151 Patientinnen mit intermediärem Risiko nach AOL hatten nach dem Test $41 \%$ ein niedriges, $44 \%$ ein intermediäres und $15 \%$ ein hohes Risiko. Die 298 Hochrisiko-Patientinnen nach AOL hatten nur zu $16 \%$ auch nach dem RS-Test ein hohes Risiko.

Fazit: Der RS beeinflusste Therapieempfehlungen von Onkologen sowie Präferenzen von Patientinnen und führte nicht selten zum Chemotherapieverzicht, wenn initial der AOL ein hohes oder intermediäres Risiko signalisiert hatte.

\section{Friederike Klein}

Levine $\mathrm{MN}$ et al. Prospective Evaluation of the 21-Gene Recurrence Score Assay for Breast Cancer Decision-Making in Ontario. J Clin Oncol. 2016;34(10):1065-71.

\title{
Lymphknoten in der Brust bei Mammakarzinom bestrahlen oder nicht?
}

\section{Was bewirkt die Bestrahlung parasternaler Lymphknoten bei Patientinnen mit frühem nodal positivem Brustkrebs?}

$B^{i}$ isher ist unklar, ob die Bestrahlung parasternaler Lymphknoten in der Brust das Überleben nach Mammakarzinom im Frühstadium verbessert: Ein möglicher Vorteil könnte durch strahleninduzierte Herzerkrankungen wieder aufgehoben werden. Von 3.089 Patientin- nen, die wegen eines frühen Mammakarzinoms operiert worden waren, erhielten diejenigen mit rechtsseitiger Erkrankung eine Bestrahlung der parasternalen Lymphknoten; diejenigen mit linksseitiger Erkrankung wurden wegen des Risikos einer strahlungsinduzierten Herzer-

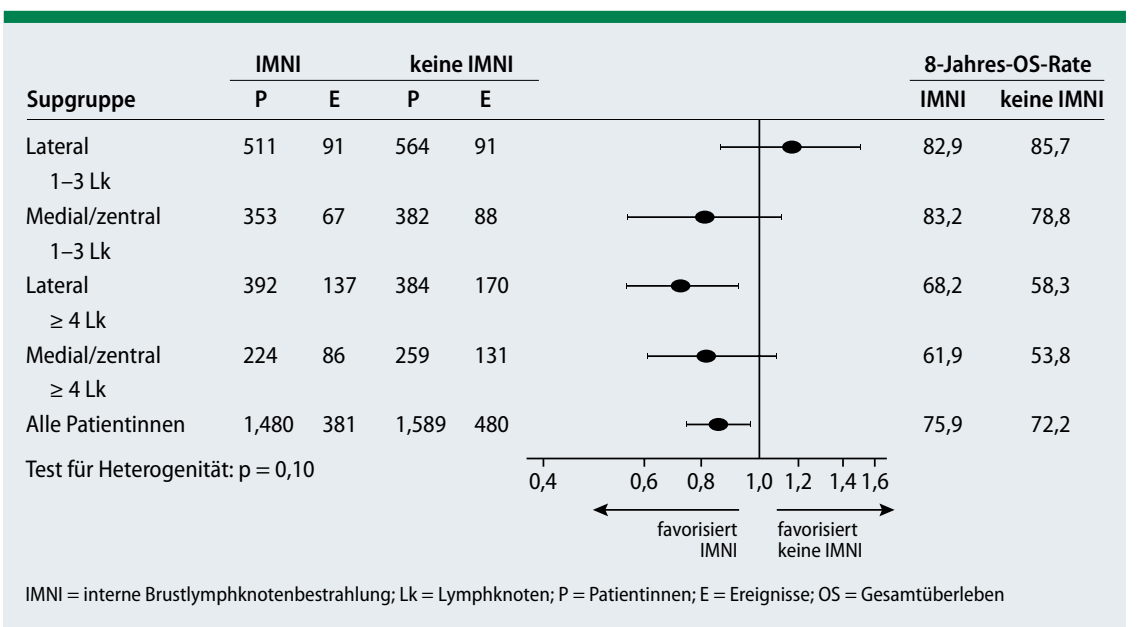

Abb. 1: Überlebensraten mit und ohne Bestrahlung der parasternalen Lymphknoten in Abhängigkeit von Lokalisation und Zahl positiver Lymphknoten. krankung nicht bestrahlt. Primärer Endpunkt war das Gesamtüberleben (OS).

Die Rate für das 8-Jahres-OS betrug $75,9 \%$ mit und $72,2 \%$ ohne Bestrahlung (Hazard Ratio [HR] 0,82; p = 0,005; Abb. 1). Die Rate für die brustkrebsbedingte Mortalität lag bei 20,9\% mit und bei $23,4 \%$ ohne Bestrahlung ( $\mathrm{HR} 0,85$; $\mathrm{p}=0,03)$. In jeder Gruppe starben vergleichbar viele Patientinnen an einer ischämischen Herzerkrankung. Der Effekt der Radiatio war stärker bei hohem Risiko für Metastasen in den parasternalen Lymphknoten. Nutzen von der Bestrahlung hatten Patientinnen mit medialem/ zentralem Tumor und/oder $\geq 4$ positiven Lymphknoten. Bei Kombination dieser Subgruppen ergab sich eine 8-JahresÜberlebensrate von $72,2 \%$ mit und $64,8 \%$ ohne Bestrahlung (HR 0,76; $\mathrm{p}=0,001$ ).

Fazit: In dieser Kohortenstudie verbesserte die Bestrahlung von parasternalen Lymphknoten in der Brust das Gesamtüberleben von Patientinnen mit frühem Mammakarzinom.

Judith Neumaier

Thorsen LB et al. DBCG-IMN: A Population-Based Cohort Study on the Effect of Internal Mammary Node Irradiation in Early Node-Positive Breast Cancer. J Clin Oncol. 2016;34(4):314-20. 